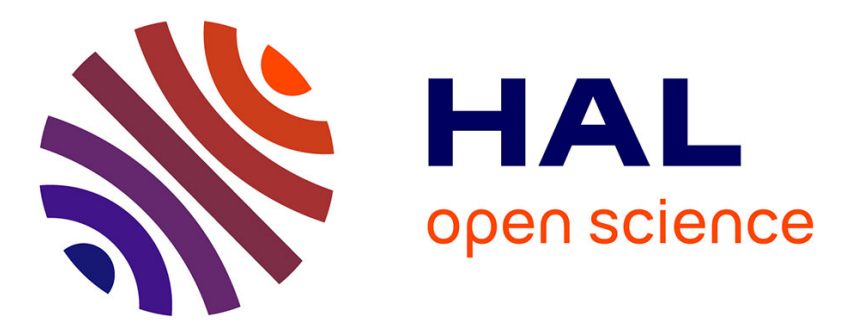

\title{
Zirconocene-catalyzed stereoselective cyclocopolymerization of 2-methyl-1,5-hexadiene with propylene
}

Manuela Bader, Gabriel Theurkauff, Katty den Dauw, Christian Lamotte, Olivier Lhost, Evqueni Kirillov, Jean-François Carpentier

\section{To cite this version:}

Manuela Bader, Gabriel Theurkauff, Katty den Dauw, Christian Lamotte, Olivier Lhost, et al.. Zirconocene-catalyzed stereoselective cyclocopolymerization of 2-methyl-1,5-hexadiene with propylene. Polymer Chemistry, 2014, 5 (19), pp.5560-5568. 10.1039/C4PY00612G . hal-01077258

HAL Id: hal-01077258 https://hal-univ-rennes1.archives-ouvertes.fr/hal-01077258

Submitted on 24 Oct 2014

HAL is a multi-disciplinary open access archive for the deposit and dissemination of scientific research documents, whether they are published or not. The documents may come from teaching and research institutions in France or abroad, or from public or private research centers.
L'archive ouverte pluridisciplinaire HAL, est destinée au dépôt et à la diffusion de documents scientifiques de niveau recherche, publiés ou non, émanant des établissements d'enseignement et de recherche français ou étrangers, des laboratoires publics ou privés. 


\section{Zirconocene-Catalyzed Stereoselective Cyclocopolymerization of 2-Methyl-}

\section{1,5-Hexadiene with Propylene}

Manuela Bader, ${ }^{\mathrm{a}, \dagger}$ Gabriel Theurkauff, ${ }^{\mathrm{a}, \dagger}$ Katty Den Dauw, ${ }^{\mathrm{b}}$ Christian Lamotte, ${ }^{\mathrm{b}}$ Olivier Lhost, ${ }^{\mathrm{b}}$ Evgueni Kirillov, ${ }^{\mathrm{a}, *}$ and Jean-François Carpentier ${ }^{\mathrm{a}, *}$

${ }^{a}$ Organometallics, Materials and Catalysis laboratories, Institut des Sciences Chimiques de Rennes, UMR 6226 CNRS-Université de Rennes 1, F-35042 Rennes, France

${ }^{b}$ Total Raffinage Chimie, Zone Industrielle Feluy C, B-7181 Seneffe, Belgium

Abstract: The copolymerization of 2-methyl-1,5-hexadiene (MHD) with propylene has been studied with different single-site group 4 metal catalysts. Systems based on ansa-zirconocene precursors such as rac- $\left\{\mathrm{Me}_{2} \mathrm{Si}(2-\mathrm{Me}-4-\mathrm{Ph}-\mathrm{Ind}\} \mathrm{ZrCl}_{2}\right.$ (1) and $C_{1^{-}}$or $C_{\mathrm{S}^{-}}$-symmetric ansa$\left\{\mathrm{CpCR}_{2} \mathrm{Flu}_{\mathrm{ZrCl}_{2}}\right.$ (2 and 3, respectively), once activated by MAO, are highly active (20-600 $\mathrm{kg}_{\mathrm{pol}} \cdot \mathrm{g}_{\mathrm{cat}} \mathrm{h}^{-1}$ at $60-70^{\circ} \mathrm{C}$ ) and yield copolymers in which MHD is cyclopolymerized as methylene-(1-methyl)-1,3-cyclopentane (MMCP) units. ${ }^{13} \mathrm{C}$ NMR studies revealed, depending on the symmetry of the precatalyst used, either highly isotactic $(\mathbf{1}, \mathbf{2})$ or syndiotactic $(\mathbf{3})$ polypropylene (PP) backbones, with isolated MMCP units. Fully trans-diastereoselective cyclopolymerization of MHD was observed with 1/MAO, while a mixture of trans and cis MMCP rings was observed with 2 and 3/MAO. The amount of MMCP units in PP (0.2-1.6 mol-\%) can be controlled by the amount of MHD in the feed. In contrast, the constrained

\footnotetext{
$\uparrow$ Those two authors equally contributed to this work.

* Correspondence to Evgueni Kirillov (evgueni.kirillov@univ-rennes1.fr) and Jean-François Carpentier (jeanfrancois.carpentier@univ-rennes1.fr); Fax: +33 (0)223236938.
} 
geometry catalyst system based on $\left\{\mathrm{C}_{5} \mathrm{Me}_{4} \mathrm{SiMe}_{2} \mathrm{~N} t \mathrm{Bu}\right\} \mathrm{TiCl}_{2}(4)$ and $\mathrm{MAO}$ showed a much lower productivity ( $c a .3 \mathrm{~kg}_{\mathrm{pol}} \cdot \mathrm{g}_{\mathrm{cat}}{ }^{-1} \mathrm{~h}^{-1}$ at $60{ }^{\circ} \mathrm{C}$ ) and yields a regioirregular, atactic copolymer in which MHD is simply vinyl-inserted in quite moderate amount (0.2 mol-\%). 


\section{Introduction}

Homopolymerization of short, yet non-conjugated diolefins such as 1,5-hexadiene leads to macromolecular structures that include in the polymer main-chain cyclic units interfaced by methylene groups, such as methylene-1,3-cyclopentane (MCP). Initially investigated with heterogeneous Ziegler-Natta catalyst systems, ${ }^{1}$ formation of such cyclopolyolefins from 1,5hexadiene was later extended with homogeneous group 4 (half) metallocenes ${ }^{2}$ and a variety of other molecular catalysts (rare earths: Sc, Y, Sm; ${ }^{3} \mathrm{~V}^{4}{ }^{4} \mathrm{Pd}^{5}$ ). The cyclopolymerization was shown to be a two-step process. The enantioface selectivity of olefin insertion determines the tacticity of the polymer, and the diastereoselectivity of the cyclisation step determines whether cis or trans rings are formed. Although the stereoselectivity of the first 1,2 insertion was controlled by the enantiomorphic site of the catalyst (if any), the diastereoselectivity of the second insertion leading to the cyclization was attributed to the bulkiness of the ligand rather than to the symmetry of the catalyst precursor. ${ }^{2}$ Hence, for instance, catalyst systems based on $\mathrm{Cp}_{2} \mathrm{ZrCl}_{2},{ }^{2 \mathrm{a}, \mathrm{c}}\{\mathrm{EBTHI}\} \mathrm{ZrCl}_{2}(\{\mathrm{EBTHI}\}=$ ethylenebis(tetrahydroindenyl $\left.)\right)^{2 \mathrm{~b}}$ and half-sandwich scandium complexes ${ }^{3 \mathrm{c}}$ yielded mainly trans cycles, while $\mathrm{Cp}^{*}{ }_{2} \mathrm{ZrCl}_{2}$ yielded mainly cis cycles. ${ }^{2 \mathrm{a}, \mathrm{c}}$

Copolymerization of 1,5 -hexadiene with ethylene ${ }^{6}$ and propylene $\mathrm{e}^{2 \mathrm{~g}, \mathrm{j}, 4,7}$ mediated by group 4 metallocenes and related single-site catalysts proceeds via intramolecular insertion of the latter diolefin and eventually leads to polyolefins incorporating 5 -membered rings. ${ }^{8}$ The copolymerization of higher diolefins such as 1,6-heptadiene, ${ }^{9}$ 1,7-octadiene and 1,9decadiene ${ }^{10}$ with ethylene and propylene was also studied with different types of catalysts. Both 1,2 insertion and eventual cyclization were observed for 1,6-heptadiene and 1,7octadiene,,${ }^{9,10}$ but only 1,2 insertion occurred for 1,9 -decadiene,,${ }^{10}$ showing that the critical step for cyclization of the monomer is the favorable formation of an intermediate where the 
pendant vinyl-end is coordinated to the metal center. Cycloinsertion of diallylsilane in copolymerization with propylene was also reported, forming 6-membered rings. ${ }^{11}$

Examples of catalysts enabling the cyclopolymerization of vinyl-vinylidene monomers are much more limited. Kesti and Waymouth have shown that the homopolymerization of 2methyl-1,5-hexadiene (MHD) catalyzed by $\mathrm{Cp}_{2}{ }_{2} \mathrm{ZrMe}_{2}$ combined with various activators (MAO, $\left.\mathrm{B}\left(\mathrm{C}_{6} \mathrm{~F}_{5}\right)_{3},\left[\mathrm{PhNHMe}_{2}\right]^{+}\left[\mathrm{B}\left(\mathrm{C}_{6} \mathrm{~F}_{5}\right)_{4}\right]^{-}\right)$produces a polymer with a repeating methylene(1-methyl)-1,3-cyclopentane (MMCP) unit (Scheme 1). ${ }^{12}$ The regio- and diastereoselective cyclopolymerization of the monomer results from the incorporation of the vinyl-end of the monomer, followed by the coordination and 1,2-insertion of the vinylidene group. The absence of $\beta$-hydrogen in the propagating species prevents $\beta$-H elimination termination reactions and the addition of another MHD molecule is favored over the $\beta$-methyl elimination. The stereochemistry of the MMCP ring was tentatively assigned as trans on the basis of NMR of oligomers and comparison with poly(methylnorbornene), a model polymer that contains only cis methylcyclopentane rings; it was further consolidated by conformational calculations. ${ }^{13}$ On the other hand, the copolymerization of ethylene with 5,7-dimethyl-1,6octadiene (5,7-DMO), a one-carbon higher homologue of MHD, with a variety of catalytic systems proceeded only via insertion of the vinyl moiety, leaving the vinylidene moiety unreacted. ${ }^{14}$ Noteworthy, the possibility to fine control the stereoselectivity of these cyclopolymerizations of vinyl-vinylidene monomers, with catalysts having drastically different stereocontrol abilities, has not been investigated yet in details.

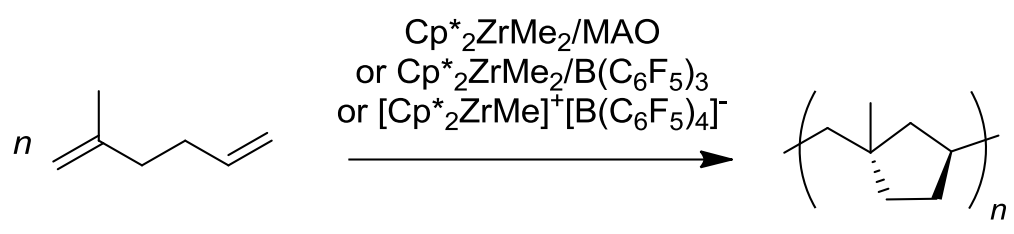


Scheme 1. Homopolymerization of MHD with repeating methylene-(1-methyl)-1,3cyclopentane (MMCP) motifs. ${ }^{12}$

Herein, we report on the first attempts to copolymerize propylene with MHD. A series of molecular catalyst precursors, including ansa-zirconocenes with quite different stereocontrol (iso- vs. syndioselective) abilities and a "constrained-geometry" hemititanocene, has been investigated. Our aim was to study their influence on the catalytic performance (productivity, comonomer incorporation) of the copolymerization process and on the microstructure of the cyclopolymers produced.

\section{Results and Discussion}

The copolymerization of MHD with propylene has been investigated with a series of ansazirconocene precatalysts (Figure 1), activated by MAO. These precatalysts were selected due

to their known propensity to produce high molecular weight isotactic $\left(\mathbf{1},{ }^{15} \mathbf{2},{ }^{16}\right)$ and syndiotactic $\left(3^{17}\right)$ polypropylenes. In addition, we have investigated the essentially nonstereoselective "constrained geometry" hemi-titanocene precatalyst $\mathbf{4}$, because of its wellknown great ability to incorporate $\alpha$-olefins. ${ }^{18}$ Representative results are reported in Table 1 . The ansa-zirconocenes and hemi-titanocene behaved quite differently and, for the sake of clarity, these two types of catalysts are discussed separately hereafter. 


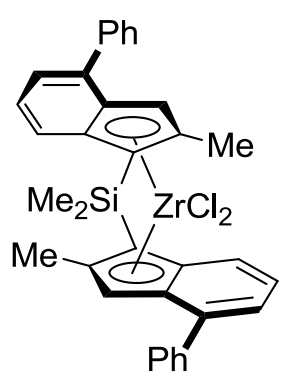

1 (rac)

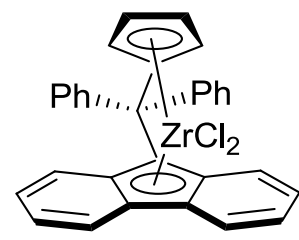

3

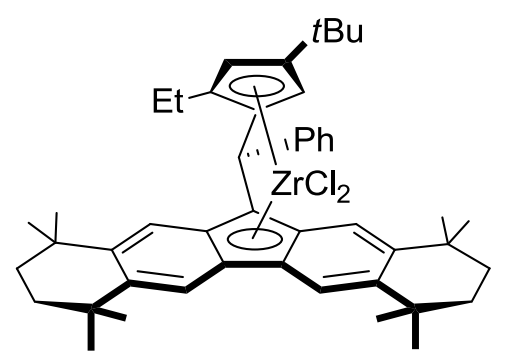

2

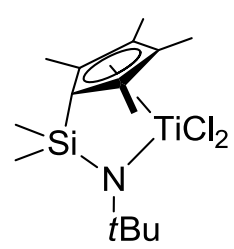

4

Figure 1. Structures of the ansa-zirconocenes and constrained geometry hemi-titanocene precatalysts used in this study for the cyclo/copolymerization of MHD with propylene.

\section{Ansa-Zirconocene Catalysts}

General Trends. All three ansa-zirconocene catalyst systems investigated afforded selectively $\mathrm{P}(\mathrm{P}-\mathrm{co}-\mathrm{MHD})$ copolymers, as indicated by the unimodal and relatively narrow molecular weight distributions determined by GPC analysis (see the Supporting Information). This is also supported by detailed ${ }^{1} \mathrm{H}$ and ${ }^{13} \mathrm{C}$ NMR analyses (vide infra) which evidenced complete cyclopolymerization of MHD with propylene, eventually providing isolated MMCP rings within the PP chain; no pendant vinylidene group was observed in any case (Scheme 2). These first observations suggest that: (i) after insertion of a vinyl MHD group, insertion of the MHD vinylidene group is favored over insertion of a propylene molecule; (ii) insertion of a propylene molecule after cycloinsertion of a MHD molecule is favored over possible $\beta$-Me elimination from a $[\mathrm{M}]-\mathrm{MMCP}$ intermediate. 


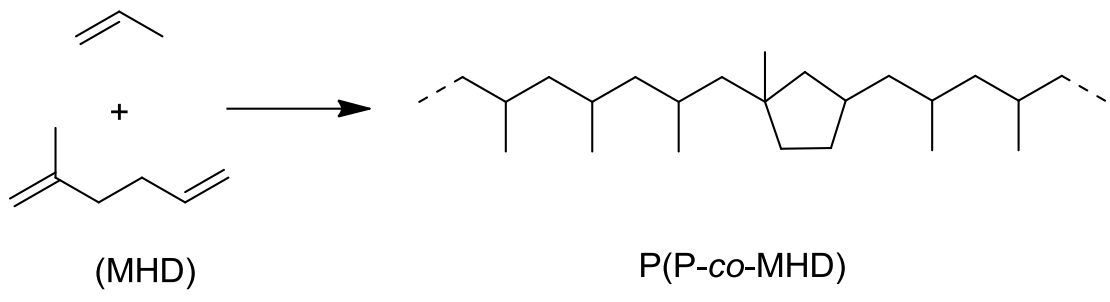

Scheme 2. Cyclopolymerization of MHD with propylene promoted by ansa-zirconocene catalysts.

Despite its efficient cyclopolymerization, MHD has a noticeable, slightly detrimental influence on the catalyst productivity/activity. As compared to simple propylene homopolymerizations, the addition of MHD decreased by $c a .25-50 \%$ the productivity of the ansa-zirconocene catalyst systems (compare entries 1 vs. 2,4 vs. 5-8, 9 vs. 10-11). ${ }^{19}$ As illustrated with system $2 / \mathrm{MAO},{ }^{20}$ the amount of MHD incorporated in the copolymers appears to be proportional to the concentration of monomer initially loaded (entries 4-8, Figure 2). Hence, from $c a .0 .34$ mol- $\%$ up to $1.3-1.6$ mol- $\%$ of MHD (that is from $c a .11$ up to 52 insertions for 10,000 carbons) are incorporated by $2 / \mathrm{MAO}$ at $[\mathrm{MHD}]_{0}$ in the range $12-80$ mmol. $\mathrm{L}^{-1}$ (entries 4-8). In addition, the MHD incorporation rate remains stable during the polymerization course (as long as the MHD concentration does not vary much), as noted with the 3/MAO system after 10 and 20 min (entries 10 and 11). Both isoselective 2 and syndioselective 3 ansa- $\left\{\mathrm{CpCR}_{2} \mathrm{Flu}\right\}$-zirconocene-based systems afforded comparable MHD incorporation rates (1.6 and $1.2 \mathrm{~mol}-\%$, respectively, at $[\mathrm{MHD}]_{0}=80 \mathrm{mmol} . \mathrm{L}^{-1}$; entries 7,8 and 10,11). Apparently, Spaleck's bis(indenyl)-zirconocene 1 showed, apart from a much higher activity than $\left\{\mathrm{CpCR}_{2} \mathrm{Flu}\right\}$-zirconocene $\mathbf{2}$, a similar ability to incorporate $\mathrm{MHD}$, with ca. 0.37 mol- $\%^{21}$ vs. 0.34 mol- $\%$ incorporation rates at $[\mathrm{MHD}]_{0}=12.0 \mathrm{mmol} . \mathrm{L}^{-1}$, respectively (entries 2 and 5). 


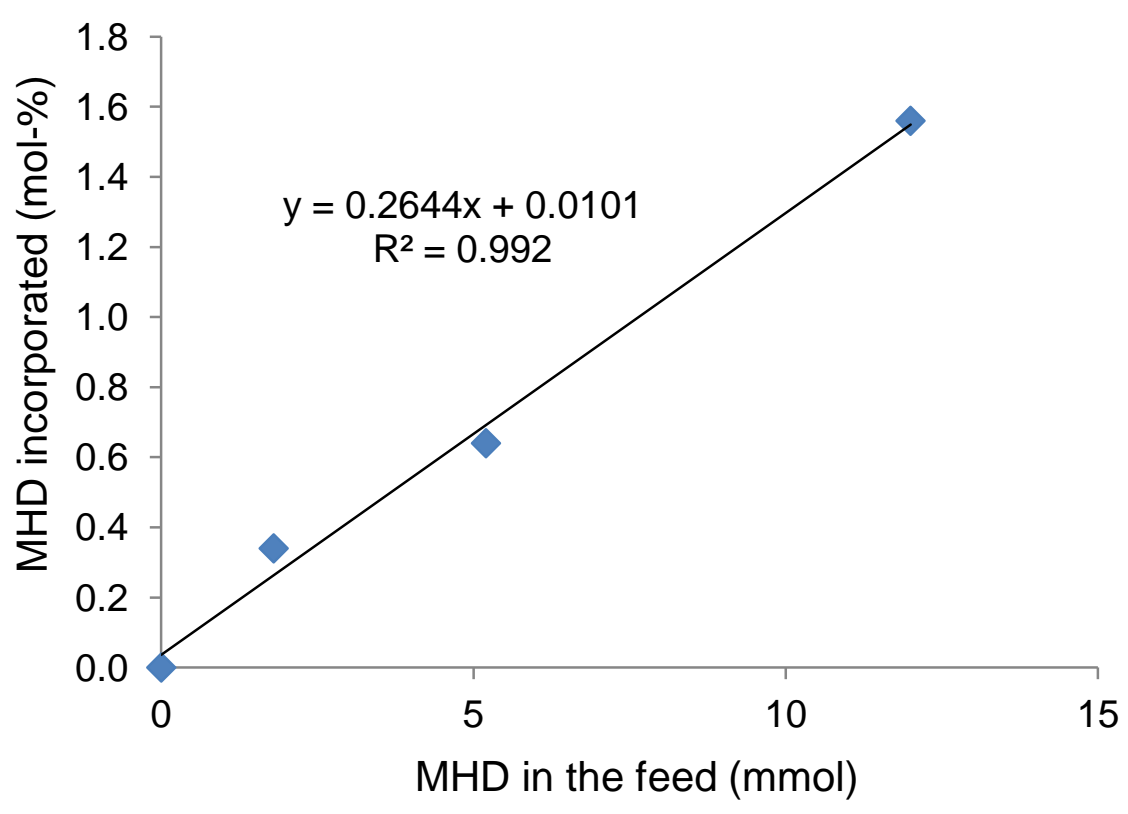

Figure 2. Plot of MHD incorporated in PP as a function of initial loading, with catalyst system 2/MAO (Table 1, entries 4, 5, 6 and 8).

For comparison purposes, the copolymerization of higher $\alpha$-olefins comparable in size with MHD but having no additional polymerizable function, namely 8-trimethylsilyl-1-octene (8-TMSO) and 7-methyl-1,6-octadiene (1,6-MOD), has been carried out using the 5/MAO system (Figure 3), which has similar reactivity and properties as $2 / \mathrm{MAO}^{16}$ (Table 1 , entries 14-16). The amounts of incorporated 8-TMSO and 1,6-MOD, which are easily determined using the TMS or internal vinylidene groups as NMR probes (see the Supporting Information), are quite comparable to those observed for MHD under similar conditions ( $c a$. 0.3 mol-\%). This confirms that it is the rate of the terminal vinyl insertion that determines the ability of cyclic incorporation of MHD. 


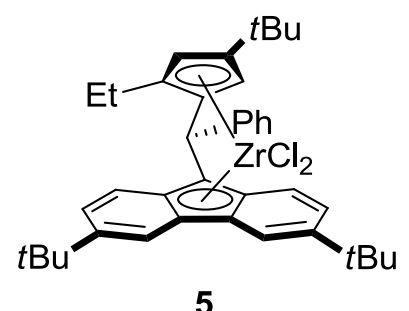

5
8-TMSO:<smiles>C=CCCCCCC[AsH3]</smiles>

1,6-MOD:

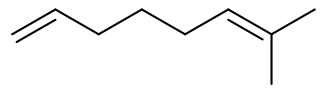

Figure 3. Structures of precatalyst 5 and higher $\alpha$-olefins 8-TMSO and 1,6-MOD.

The cyclopolymerization of MHD affects the molecular features of the PP produced. The $\mathrm{P}(\mathrm{P}-\mathrm{co}-\mathrm{MHD})$ copolymers featured systematically lower molecular weights than the corresponding homoPP (entries 1-2, 4-8 and 9-11). This decrease of the molecular weight follows the same trend as the decrease of the activity/productivity. The incorporation of a monomer more difficult to insert than propylene (i.e., the vinylidene moiety of MHD) results in a kind of "dormant" species and likely leads to a higher probability for this latter species to undergo termination or chain transfer to aluminum reactions. This might also account for the the larger dispersity (yet still unimodal) observed with the highly active catalyst 1/MAO (entry 2). On the other hand, copolymers produced by $2 / \mathrm{MAO}$ and $3 / \mathrm{MAO}$ (entries $5-8$ and 10,11) show a relatively narrow dispersity, comparable with that of homoPPs produced by the same catalyst (entries 4 and 9, respectively).

As anticipated, the incorporation of little MHD as MMCP rings induced a small decrease in the stereoregularity compared to the corresponding homoPP, that is $c a .2-3 \%$ (at the $m^{4}$ level) for 2 (entries $4-8$ ) to $c a$. $4 \%$ for $\mathbf{1}$ (entries 1-3). Syndioselective catalyst 3 followed the same trend with a drop of 3\% at the $r^{4}$ level (entries 9-11). The presence of MMCP rings in the polymer backbone also decreased the crystallinity of the copolymers, as evidenced by a pronounced decrease of the melting temperature up to $11{ }^{\circ} \mathrm{C}$ in the case of the copolymer produced with 1/MAO (entries 1-3). For less stereoregular copolymers produced 
with $2 / \mathrm{MAO}$ or $3 / \mathrm{MAO}$, a difference of only $1-2{ }^{\circ} \mathrm{C}$ was noted in the $T_{\mathrm{m}}$ values (entries $4-8$ and 9-11).

Microstructural NMR Analysis. The microstructure of the $\mathrm{P}(\mathrm{P}-\mathrm{co}-\mathrm{MHD})$ copolymers produced with the three ansa-zirconocene catalysts was analyzed by ${ }^{13} \mathrm{C}\left\{{ }^{1} \mathrm{H}\right\}$ NMR spectroscopy. It was compared with that of the corresponding PP homopolymers in order to distinguish the resonances specific to the MMCP motifs from those which correspond to intrinsic branching and stereo/regio-defects in the PP backbone (not relevant to this study). In the NMR spectra of isotactic and syndiotactic polymers (Figures 4 and 5, respectively), the absence of a resonance at $\delta c a .34 .5 \mathrm{ppm}$, which is observed when the cyclic MMCP units are adjacent to one another as in PMHD homopolymers [for the $\mathrm{C} 4$ methylene group], ${ }^{12}$ indicates that all of the MMCP units are separated by propylene units in the copolymers; this was not unexpected when considering the low MHD incorporation rates $(<2$ mol- $\%)$.

Depending on the ansa-zirconocene catalyst used, one or two sets of resonances assigned to the MMCP motifs incorporated in the PP backbone were identified. The two sets of signals for the MMCP motifs produced by syndioselective catalyst 3/MAO (identified with markers + (major set) and $\times$ (minor set) $)$ are different from the signals identified for the corresponding motifs formed by isoselective catalysts 1/MAO and 2/MAO (identified with markers $*$ (major) and ${ }^{\circ}$ (minor) ${ }^{22}$ ) (Table 2). As described hereafter, each of these four sets of signals corresponds to a specific MMCP stereoisomer (trans/cis) formed upon vinylidene insertion within either an isotactic or a syndiotactic PP backbone (Scheme 3, microstructures trans-iso/cis-iso and trans-syndio/cis-syndio). A ${ }^{13} \mathrm{C}-{ }^{13} \mathrm{C}$ INADEQUATE NMR experiment was performed on a copolymer produced by $2 / \mathrm{MAO}$ and containing 0.5 mol- $\%$ of $\mathrm{MHD}$ (Table 1, entry 6), enabling a complete assignment of the major set of signals observed for the MMCP motifs (Figure 6, Table 2; the minor set was of too low intensity to observe cross- 
peaks); only the resonance of the 1-methyl $\mathrm{MMCP}(\delta c a .28 .5 \mathrm{ppm})^{12}$ could not be unambiguously identified, as it overlaps with the $C \mathrm{H}$ signals of the iPP backbone.

(insert Figures 4 and 5 here)

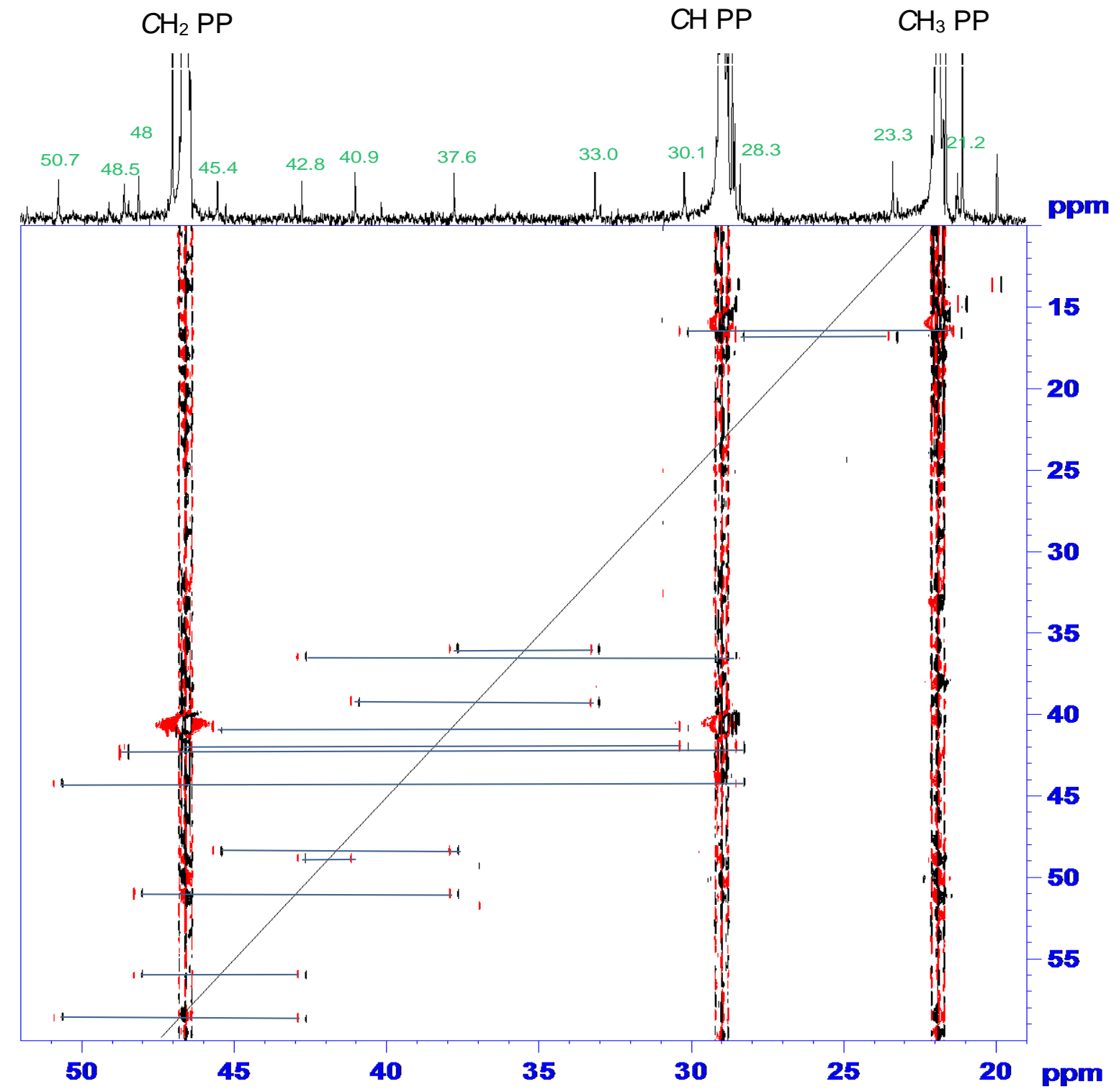

Figure 6. ${ }^{13} \mathrm{C}_{-}{ }^{13} \mathrm{C}$ INADEQUATE NMR spectrum (1,2,4-trichlorobenzene/ $\mathrm{C}_{6} \mathrm{D}_{6}(5: 1), 125$ $\left.\mathrm{MHz}, 135^{\circ} \mathrm{C}\right)$ of a $\mathrm{P}(\mathrm{P}-\mathrm{co}-\mathrm{MHD})$ copolymer produced by 2/MAO (Table 1, entry 6). 
Table 2. Assignment of individual sets of ${ }^{13} \mathrm{C}$ NMR resonances (in ppm) for cyclic MMCP motifs in isotactic and syndiotactic PP backbones. The right structure shows experimental chemical shifts for the major set $(*)$ of resonances in an iPP backbone and (in parentheses) the corresponding calculated chemical shifts (ACD Lab).

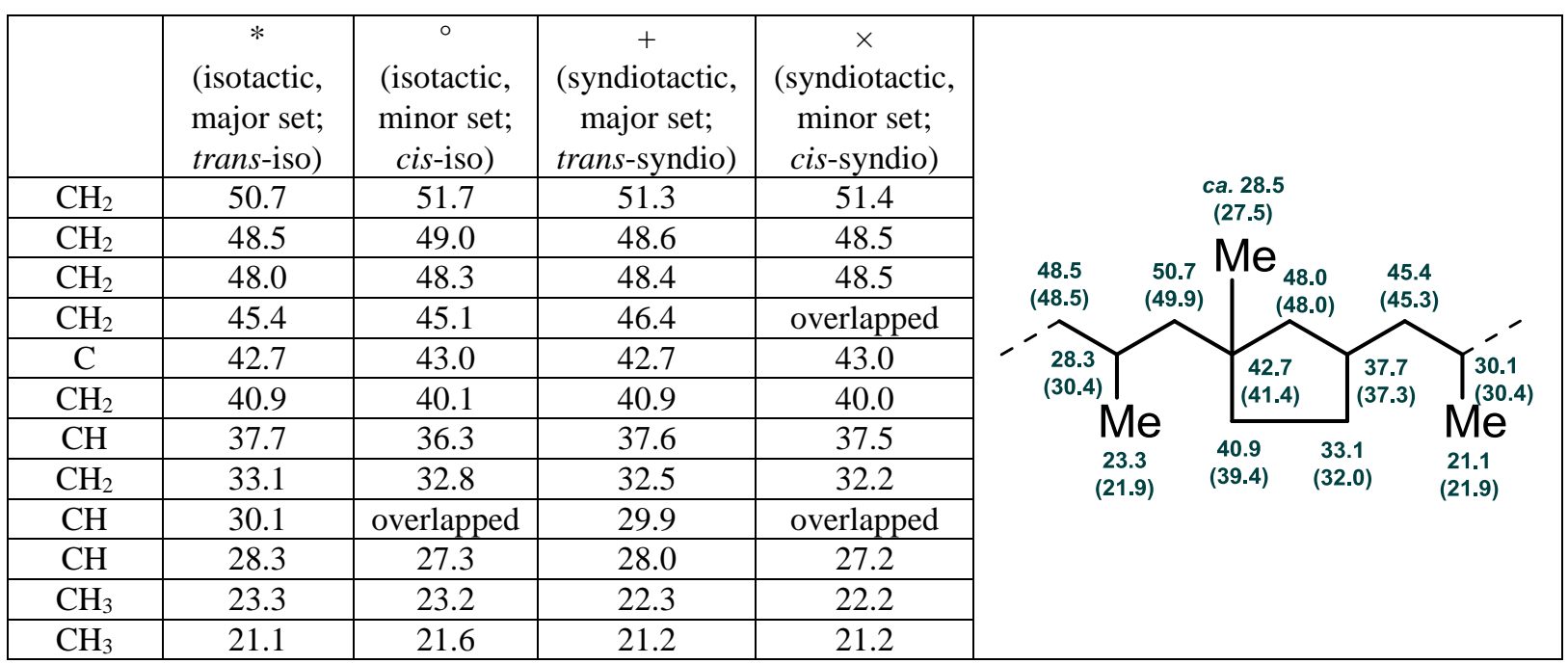
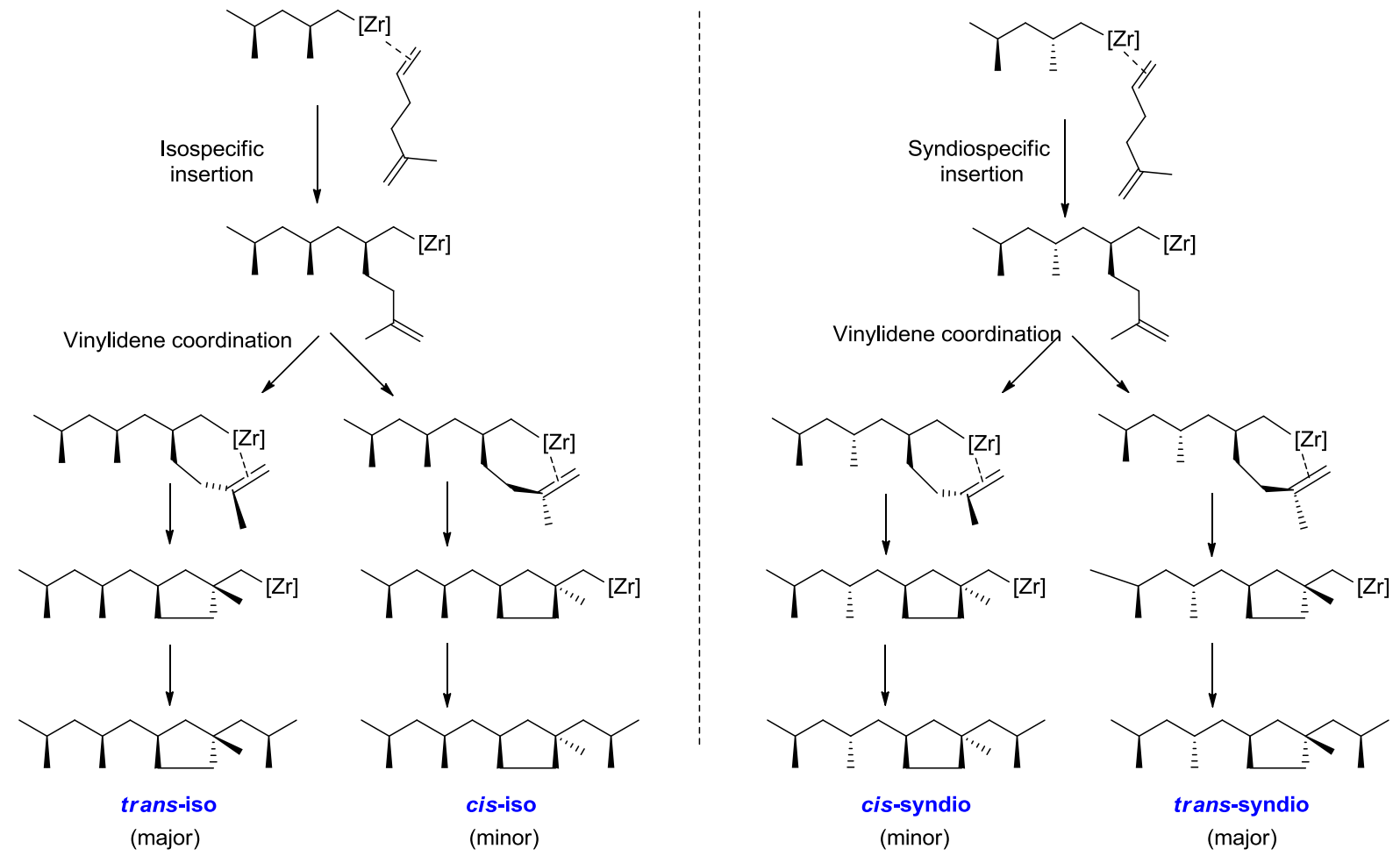
Scheme 3. Cyclopolymerization mechanism of MHD with propylene by isoselective (left) and syndioselective (right) ansa-zirconocene catalysts, leading to the formation of two trans/cis MMCP stereoisomers in iPP and sPP backbones, respectively.

In fact, the use of stereoselective catalysts for the copolymerization of MHD and propylene reduces the number of possible stereoisomers. With the $\left\{\mathrm{CpCR}_{2} \mathrm{Flu}\right\}$-type isoselective 2/MAO and syndioselective 3/MAO catalysts, two sets of resonances (* (major) ${ }^{\circ}$ $(\text { minor })^{22}$ and + (major) $\times($ minor $)$, respectively) were clearly observed in the ${ }^{13} \mathrm{C} \mathrm{NMR}$ spectra. On the other hand, the incorporation of MHD by isoselective bis(indenyl) catalyst 1/MAO leads to only one observable set (*). Based on earlier observations by Waymouth et al. ${ }^{12}$ Naga et al. ${ }^{7 \mathrm{a}}$ and computations by Cavallo et al., ${ }^{13}$ this latter set can be confidently assigned to the trans-iso isomer; similarly, the major and minor sets derived from 2 and 3/MAO can be assigned to the trans-iso and cis-iso, and trans-syndio and cis-syndio isomers, respectively. This shows that vinylidene insertion is more stereoselective with $\mathbf{1}$ than with $\mathbf{2}$ and 3. This is line with the higher stereoselectivity of this former catalyst system toward propylene homopolymerization, as compared to the latter $\left\{\mathrm{CpCR}_{2} \mathrm{Flu}\right\}$-type catalysts $(97.7 \%$ $\left[\mathrm{m}^{4}\right]$ for 1/MAO vs. $94.1 \%\left[\mathrm{~m}^{4}\right]$ for 2/MAO; Table 1, entries 1 and 4, respectively).

Yet, this difference in isoselectivity between catalysts might not be important enough to justify the absence of the minor MMCP stereoisomer in the copolymer produced by 1/MAO. In line with previous reports, ${ }^{7 a, 12,13}$ we suspect that the different geometries between, on one hand, the $\left\{\mathrm{CpCR}_{2} \mathrm{Flu}\right\}$-type catalysts based on $\mathbf{2}$ and $\mathbf{3}$ and, on the other hand, the bis(indenyl) catalyst $\mathbf{1}$ might also account for the higher stereoselectivity of the process. The key factor in the formation of those stereoisomers is which enantioface of vinylidene is coordinated to the metal center (Scheme 3). In this process, the distance between the free coordination sites and the steric hindrance between the bridging carbons of MHD and the 
substituents of the ligand certainly are determining factors in the formation of either one or the other intermediate.

\section{Hemi-Titanocene "Constrained Geometry" Catalyst}

The "constrained geometry" 4/MAO catalyst system behaved quite differently from the ansazirconocene ones (Table 1, entries 12, 13). First, under comparable conditions, the catalytic productivity was lower by one or two orders of magnitude. More, although a copolymer with a relatively narrow, unimodal distribution was indeed produced, no cyclization of MHD was observed (Scheme 4). The ${ }^{13} \mathrm{C}$ NMR spectra of copolymers produced with catalyst $4 / \mathrm{MAO}$ proved much more complicated than those of polymers prepared with stereoselective ansazirconocene catalysts (Figure 7). Despite the complexity of the spectra, arising as anticipated from the presence of many regio-errors (2,1-insertions, as evidenced by signals in the $\delta 15-17$ ppm region $)^{23}$ and the absence of stereocontrol, ${ }^{18}$ informative observations could be made: i) $\mathrm{CH}_{2}$ signals at $\delta 48-50 \mathrm{ppm}$, characteristic of MMCP rings (vide supra) were absent; ii) instead, signals at $\delta 110.0$ and $146.1 \mathrm{ppm}$, assignable to the pendant vinylidene group of vinyl-inserted MHD, were observed. ${ }^{24}$ Simple vinyl-insertion of MHD was corroborated by the observation in the ${ }^{1} \mathrm{H}$ NMR spectra of signals at $\delta 4.69$ and $4.67 \mathrm{ppm}$ for the pendant vinylidene group (see Figure S2 in the Supporting Information). ${ }^{24}$

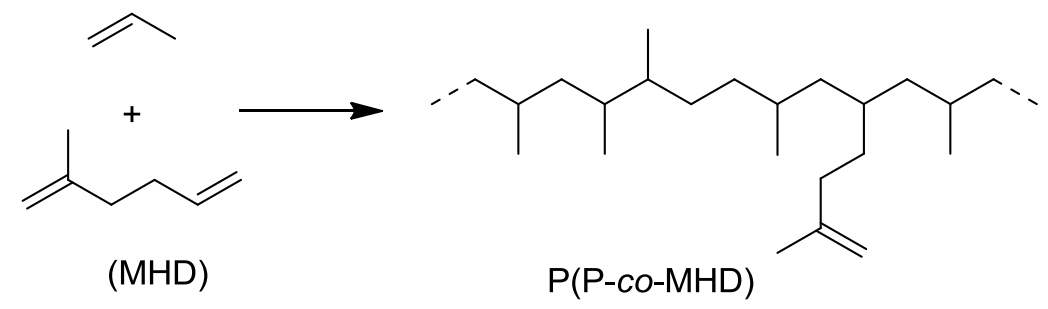


Scheme 4. Vinyl-copolymerization of MHD with propylene promoted by hemi-titanocene “constrained geometry" catalyst 4/MAO.

(insert Figure 7 here)

The amount of MHD inserted was estimated by ${ }^{13} \mathrm{C}$ NMR to be $c a .0 .2 \mathrm{~mol}-\%$, that is ca. 5 fold less than with ansa-zirconocenes under similar conditions (compare entries 13 vs. 7/8 and 10/11). Overall, these data show that the 4/MAO system polymerizes much more easily vinyl than vinylidene groups. This was somehow unexpected considering that constrained geometry titanium catalysts have been reported to promote the copolymerization of isoalkenes with olefins (ethylene), yet with bimetallic catalysts leading to incorporation rates significantly enhanced as compared to those achieved with monometallic ones. ${ }^{25}$

\section{Summary}

The copolymerization of MHD with propylene by isoselective and syndioselective ansa-zirconocene catalysts leads to the production of copolymers in which MHD is selectively incorporated as methylene-(1-methyl)-1,3-cyclopentane (MMCP) units via consecutive insertion of the vinyl and vinylidene bonds. The MMCP rings feature specific ${ }^{13} \mathrm{C}$ NMR resonances, depending on their trans/cis configuration and on the isotactic/syndiotactic PP backbone, and some of them could be assigned by a ${ }^{13} \mathrm{C}-{ }^{13} \mathrm{C}$ INADEQUATE NMR experiment. Fully trans-diastereoselective cyclopolymerization of MHD was observed with the bis $\{$ indenyl $\}$ catalyst $\mathbf{1} / \mathrm{MAO}$, while a mixture of trans (major) and cis (minor) MMCP rings was observed with the $\left\{\mathrm{CpCR}_{2} \mathrm{Flu}\right\}$-type catalysts 2 and $3 / \mathrm{MAO}$. This behavior is attributed to the intrinsic higher stereoselectivity of the former catalyst and geometric differences between the catalysts. The copolymers produced with 2 and 3/MAO, which 
contains up to $1.6 \mathrm{~mol}-\%$ of $\mathrm{MHD} / \mathrm{MMCP}$, have melting temperatures close to those of the corresponding i/sPP homopolymers. In contrast, incorporation of $0.4-0.6$ mol-\% of MHD in iPP by 1/MAO resulted in a much more pronounced drop of the melting temperature.

\section{Experimental section}

General. All manipulations were performed under a purified argon atmosphere using standard Schlenk techniques or in a glovebox. Solvents were distilled $\mathrm{Na} / \mathrm{K}$ alloy (toluene, hexane, pentane) under argon, degassed thoroughly and stored under argon prior to use. Ansa-metallocene $r a c-\left\{\mathrm{Me}_{2} \mathrm{Si}(2-\mathrm{Me}-4-\mathrm{Ph}-\mathrm{Ind}\} \mathrm{ZrCl}_{2}\right.$ (1) was generously provided by Total Raffinage Chimie. Ansa-metallocenes $2,{ }^{16} \mathbf{3}^{26}$ and $\mathbf{5}^{16}$ were synthesized as described in the literature. Hemi-titanocene $\left\{\mathrm{C}_{5} \mathrm{Me}_{4} \mathrm{SiMe}_{2} \mathrm{~N} t \mathrm{Bu}\right\} \mathrm{TiCl}_{2}$ (4) was purchased from Boulder Scientific. Methyl-1,5-hexadiene (MHD), 8-trimethylsilyl-1-octene (8-TMSO) and 7-methyl1,6-octadiene (1,6-MOD) were purchased from Aldrich, and kept over activated molecular sieves. Propylene (99.99\%) was purchased from Air Liquide and used as received. MAO (30 wt-\% solution in toluene, Albermale; contains ca. 10 wt- $\%$ of free $\mathrm{AlMe}_{3}$ ) was used as received.

${ }^{13} \mathrm{C}\left\{{ }^{1} \mathrm{H}\right\}$ NMR analyses of polymer samples were run in the research center of Total Raffinage-Chimie in Feluy (Belgium) on a Avance 500 Bruker spectrometer equipped with a cryoprobe using the following conditions: solutions of $c a .200-700 \mathrm{mg}$ of polymer in $\mathrm{Cl}_{2} \mathrm{CDCDCl}_{2}$ or in a $1,2,4$-trichlorobenzene/ $\mathrm{C}_{6} \mathrm{D}_{6}(5: 1)$ mixture at $135{ }^{\circ} \mathrm{C}$ in $10 \mathrm{~mm}$ tubes, inverse gated experiment, pulse angle $=90^{\circ}$, delay $=30 \mathrm{~s}$, acquisition time $=1.25 \mathrm{~s}$, number of scans $=500-1,000 .{ }^{13} \mathrm{C}$ chemical shifts are reported in ppm using $\mathrm{Me}_{3} \mathrm{SiOSiMe}_{3}(\delta 2.03$ ppm; equivalent to $\delta 0.00 \mathrm{ppm}$ for $\mathrm{SiMe}_{4}$ ) as internal standard. The MHD incorporation rate was determined as MHD (mol-\%) $=$ [average of integral values of MMCP signals] / [integral value for $\mathrm{CH}$ of $\mathrm{PP}+$ average of integral values of MMCP signals $] \times 100$. The ${ }^{13} \mathrm{C}-{ }^{13} \mathrm{C}$ 
INADEQUATE spectrum was recorded using $700 \mathrm{mg}$ of polymer dissolved in a $10 \mathrm{~mm}$ tube in a $1,2,4$-trichlorobenzene/ $\mathrm{C}_{6} \mathrm{D}_{6}(5: 1)$ mixture at $135{ }^{\circ} \mathrm{C}$, with a $50 \mathrm{ppm}$ spectral width centered at $\delta 34 \mathrm{ppm}$, using 240 increments containing each 384 scans, and a delay of $4 \mathrm{~s}$.

DSC measurements were performed on a SETARAM Instrumentation DSC 131 differential scanning calorimeter at a heating rate of $10{ }^{\circ} \mathrm{C} \cdot \mathrm{min}^{-1}$; first and second runs were recorded after cooling to $30{ }^{\circ} \mathrm{C}$; the melting temperatures reported in tables correspond to the second run. GPC analyses were carried out in 1,2,4-trichlorobenzene at $135{ }^{\circ} \mathrm{C}$ in the research center of Total Raffinage-Chimie in Feluy (Belgium), using polystyrene standards for universal calibration.

Propylene/2-methyl-1,5-hexadiene copolymerization procedure. Copolymerization experiments were performed in a $300 \mathrm{~mL}$ high-pressure glass reactor equipped with a mechanical stirrer (Pelton turbine) and externally heated with a double mantle with a thermostated circulating water bath. The reactor was charged with toluene ( 80 to $150 \mathrm{~mL}$ ), the appropriate amount of 2-methyl-1,5-hexadiene (MHD) and MAO (1.5 mL of a $30 \mathrm{wt}-\%$ solution in toluene), and propylene (5 bar) was introduced. The reactor was thermally equilibrated at the desired temperature for $30 \mathrm{~min}$. Propylene pressure was decreased to $1 \mathrm{bar}$, and a solution of the catalyst precursor in toluene $(c a .2 \mathrm{~mL})$ was added by syringe. The propylene pressure was immediately increased to 5 bar (kept constant with a back regulator) and the solution was stirred for the desired time. The temperature inside the reactor was monitored using a thermocouple. The polymerization was stopped by venting the vessel and quenching with a $10 \mathrm{wt}-\%$ solution of aqueous $\mathrm{HCl}$ in methanol (ca. $3 \mathrm{~mL})$. The polymer was precipitated in methanol (ca. $200 \mathrm{~mL})$ and $35 \mathrm{wt}-\%$ aqueous $\mathrm{HCl}(c a .1 \mathrm{~mL})$ was added to dissolve possible catalyst residues. The polymer was collected by filtration, washed with methanol (ca. $200 \mathrm{~mL}$ ), and dried under vacuum overnight. Homopolymerization of 
propylene (Table 1 , entries $1,4,9,12,14)$ and copolymerization of propylene with other model $\alpha$-olefins (Table 1, entries 15 and 16) were conducted in a similar way.

Supporting Information Available. ${ }^{1} \mathrm{H}$ NMR spectrum of a $\mathrm{P}(\mathrm{P}-\mathrm{co}-\mathrm{MHB})$ copolymer produced with "constrained geometry" catalyst 4/MAO; ${ }^{1} \mathrm{H}$ NMR spectra of copolymers of propylene with 8-TMSO and 1,6-MOD; representative GPC and DSC traces of copolymers.

\section{Acknowledgements}

This work was financially supported by Total Raffinage-Chimie (PhD grants to MB and GT). J.-M. Brusson, O. Miserque, M. Slawinski, and J. Wassenar (Total Corporate Research, Total Raffinage-Chimie) are gratefully acknowledged for stimulating discussions.

\section{Notes and References}

1 (a) C. S. Marvel and J. K. Stille, J. Am. Chem. Soc., 1958, 80, 1740; (b) H. S. Makovski, K. C. Shim and Z. W. Wilshinsky, J. Polym. Sci. A, 1964, 2, 1549; (c) H. S. Makovski, B. K. C Shim and W. P. Cain, U.S. Pat., 3,357,961, 1967; (d) S. G. Olson, U. S. Pat. 3,435,020, 1969; (e) H. N. Cheng and N. P. Khasat, J. Appl. Polym. Sci., $1988,35,825$.

2 (a) L. Resconi and R. M. Waymouth, J. Am. Chem. Soc., 1990, 112, 4953; (b) G. W. Coates and R. M. Waymouth, J. Am. Chem. Soc., 1991, 113, 6270; (c) A. L. Mogstad and R. M. Waymouth, Macromolecules, 1992, 25, 2282; (d) G. W. Coates and R. M. Waymouth, J. Am. Chem. Soc., 1993, 115, 91; (e) L. Cavallo, G. Guerra, P. Corradini, L. Resconi and R. M. Waymouth, Macromolecules, 1993, 26, 260; (f) M. Mitani, K. Oouchi, M. Hayakawa, T. Yamada and T. Mukaiyama, Chem. Lett., 1995, 905; (g) F. 
G. Sernetz, R. Mulhaupt and R. M. Waymouth, Polym. Bull., 1997, 38, 141; (h) G. Rodriguez and G. C. Bazan, J. Am. Chem. Soc., 1997, 119, 343; (i) K. C. Jayaratne, R. J. Keaton, D. A. Henningsen and L. R. Sita, J. Am. Chem. Soc., 2000, 122, 10490; (j) P. D. Hustad and C. W. Coates, J. Am. Chem. Soc., 2002, 124, 11578; (k) K. Nomura, Y. Hatanaka, H. Okumura, M. Fujiki and K. Hasegawa, Macromolecules, 2004, 37, 1693; (l) K. Nomura, A. Takemoto, Y. Hatanaka, H. Okumura, M. Fujiki and K. Hasegawa, Macromolecules, 2006, 39, 4009; (m) E. J. Stoebenau and R. F. Jordan, J. Am. Chem. Soc., 2006, 128, 8162; (n) A. Yeori, I. Goldberg, M. Shuster and M. Kol, J. Am. Chem. Soc., 2006, 128, 13062; (o) A. Yeori, I. Goldberg and M. Kol, Macromolecules, 2007, 40, 8521 .

(a) C. J. Schaverien, Organometallics, 1994, 13, 69; (b) H. Yasuda and E. Ihara, Tetrahedron, 1995, 51, 4563; (b) E. Ihara, M. Nodono, K. Katsura, Y. Adachi, H. Yasuda, M. Yamagashira, H. Hashimoto, N. Kanehisa and Y. Kai, Organometallics, 1998, 17, 3945; (c) F. Guo, M. Nishiura, H. Koshino and Z. Hou, Macromolecules, 2011, 44, 6335.

$4 \quad$ Y. Doi, N. Tokuhiro and K. Soga, Makromol. Chem., 1989, 190, 643.

5 For a review on stereo-controlled synthesis of polyolefins with cycloalkane groups by late transition metal catalysts, see: D. Takeuchi, Polymer J., 2012, 44, 919. N. Choo and R. M. Waymouth, J. Am. Chem. Soc., 2002, 124, 4188; (c) N. Naga and Y. Imanishi, Macromol. Chem. Phys., 2002, 203, 771; (d) M. Napoli, C. Costabile, S. Pragliola and P. Longo, Macromolecules, 2005, 38, 5493. (a) N. Naga, T. Shiono and T. Ikeda, Macromolecules, 1999, 32, 1348; (b) I. Kim, Y. S. Shin and J. K. Lee, J. Polym. Sci. A, 2000, 38, 1590. 
Interest in polyolefins incorporating cyclic groups is a result of the improved transparency and high glass transition temperatures of such materials. See O. Henschke, F. Köller and M. Arnold, Macromol. Rapid Commun., 1997, 18, 617.

(a) D. Takeuchi, R. Matsuura and K. Osakada, Macromol. Rapid Commun., 2008, 29, 1932; (b) F. Guo, M. Nishiura, H. Koshino and Z. Hou, Macromolecules, 2011, 44, 2400. N. Naga and Y. Imanishi, Macromol. Chem. Phys., 2002, 203, 2155; N. Naga, J. Polym. Sci. A, 2006, 44, 6083. M. R. Kesti and R. M. Waymouth, J. Am. Chem. Soc., 1992, 114, 3565.

L. Cavallo, G. Guerra, P. Corradini, L. Resconi and R. M. Waymouth, Macromolecules, 1993, 26, 260.

J. M. Santos, M. R. Ribeiro, M. F. Portela, H. Cramail and A. Deffieux, Macromol. Chem. Phys., 2001, 202, 3043.

(a) W. Spaleck, M. Antberg, J. Rohrmann, A. Winter, B. Bachmann, P. Kiprof, J. Behm and W. A. Herrmann, Angew. Chem. Int. Ed. Engl., 1992, 31, 1347; (b) W. Spaleck, F. Kuber, A. Winter, J. Rohrmann, B. Bachmann, M. Antberg, V. Dolle and E. F. Paulus, Organometallics, 1994, 13, 954; (c) U. Stehling, J. Diebold, R. Kirsten, W. Roll, H. H. Brintzinger, S. Jungling, R. Mulhaupt and F. Langhauser, Organometallics, 1994, 13, 964; (d) A. Schöbel, E. Herdtweck, M. Parkinson and B. Rieger, Chem. Eur. J., 2012, 18,4174 (a) E. Kirillov, N. Marquet, A. Razavi, V. Belia, F. Hampel, T. Roisnel, J. A. Gladysz and J.-F. Carpentier, Organometallics, 2010, 29, 5073; (b) E. Kirillov, N. Marquet, M. Bader, A. Razavi, V. Belia, F. Hampel, T. Roisnel, J. A. Gladysz and J.-F. Carpentier, 
Organometallics, 2011, 30, 263; (c) M. Bader, N. Marquet, E. Kirillov, T. Roisnel, A. Razavi, O. Lhost and J.-F. Carpentier, Organometallics, 2012, 31, 8375.

(a) W. Song, M. D. Rausch and J. C. W. Chien, J. Polym. Sci. A Polym. Chem., 1996, 34, 2945; (b) S. A. Miller and J. E. Bercaw, Organometallics, 2004, 23, 1777; (c) M.-C. Chen, J. A. S. Roberts and T. J. Marks, J. Am. Chem. Soc., 2004, 126, 4605.

(a) P. J. Shapiro, E. Bunel, W. P. Schaefer and J. E. Bercaw, Organometallics, 1990, 9, 867; (b) J. C. Stevens, F. J. Timmers, G. Rosen, G. W. Knight and S. Y. Lai (Dow Chemical Co.), Eur. Pat. App., EP 0416815 A2, 1991; (c) J. A. Canich, (Exxon Chemical Co.), Eur. Pat. App., EP 0420436 A1, 1991; (d) A. L. McKnight and R. M. Waymouth, Chem. Rev., 1998, 98, 2587; (e) H. Braunschweig and F. M. Breitling, Coord. Chem. Rev., 2006, 250, 2691.

All reactions were typically conducted at a consigned temperature of $60{ }^{\circ} \mathrm{C}$. However, with highly active systems such as $\mathbf{1}, \mathbf{2}$ and $\mathbf{3} / \mathrm{MAO}$, and despite the low precatalyst loading and vigorous cooling system used, it often turned out difficult to evacuate the exothermicity of the polymerization; the temperature in the reactor hence often reached $70-75^{\circ} \mathrm{C}$ (see Table 1). This increase of the reaction temperature accounts for some different productivities of a given system.

This study of MHD incorporation rate as a function of MHD loading could not be easily performed with 1/MAO, as this is system is so active that it exhausts rapidly MHD from the reaction medium.

Note yet that, as total conversion of MHD was achieved for this run with $\mathbf{1}$, it is likely that the amount of incorporated comonomer would have been higher if the polymerization was stopped before running out of MHD. However, due to technical constraints with this highly active system, this aspect was no further investigated. 
22 The intensity ratio between the major $(*)$ and minor $\left(^{\circ}\right)$ sets of resonances was determined to be 73:27 in $\mathrm{P}(\mathrm{P}-\mathrm{co}-\mathrm{MHD})$ copolymers produced by 2 (Table 1 , entries 5 and 6).

23 Most of the signals in the region $\delta 30-45 \mathrm{ppm}$ are also assignable to regio/stereoerrors in the polypropylene backbone.

24 Regular vinylidene groups in PP are observed at $\delta 111.6$ and $144.5 \mathrm{ppm}$ in ${ }^{13} \mathrm{C} \mathrm{NMR}$ and at $\delta 4.64$ and $4.70 \mathrm{ppm}$ in ${ }^{1} \mathrm{H}$ NMR. The $0.06 \mathrm{ppm}$ difference between the latter ${ }^{1} \mathrm{H}$ signals is significantly larger than the $0.02 \mathrm{ppm}$ difference observed in the $\mathrm{P}(\mathrm{P}-\mathrm{co}$ MHD) copolymers produced by 4/MAO; see: L. Resconi, F. Piemontesi, I. Camurati, O. Sudmeijer, I. E. Nifant'ev, P. V. Ivvchenko and L .G. Kuz'mina, J. Am. Chem. Soc., 1998, 120, 2308

(a) H. Li, L. Li, T. J. Marks, L. Liable-Sands and A. L. Rheingold, J. Am. Chem. Soc., 2003, 125, 10788; (b) M. Delferro and T. J. Marks, Chem. Rev., 2011, 111, 2450.

A. Razavi and J. L. Atwood, J. Organomet. Chem., 1992, 459, 117. 
Table 1. Copolymerization of propylene with MHD and model $\alpha$-olefins by catalytic systems $\mathbf{1}-\mathbf{5} / \mathrm{MAO}^{\mathrm{a}}$

\begin{tabular}{|c|c|c|c|c|c|c|c|c|c|c|c|c|c|c|c|}
\hline Ent. & Precat. & $\begin{array}{c}{[\mathrm{Zr}]} \\
{\left[\mu \mathrm{mol} . \mathrm{L}^{-1}\right]}\end{array}$ & {$[\mathrm{Al}] /[\mathrm{Zr}]$} & Comon. & $\begin{array}{c}\mathrm{n}_{\mathrm{Com}} \\
{[\mathrm{mmol}]}\end{array}$ & $\begin{array}{l}T_{\text {polym }} \\
{\left[{ }^{\circ} \mathrm{C}\right]^{\mathrm{d}}}\end{array}$ & $\begin{array}{r}\mathrm{m}_{\mathrm{pp}} \\
{[\mathrm{g}]}\end{array}$ & $\begin{array}{c}\text { Prod. } \\
{\left[\mathrm{kg}_{\mathrm{PP}} \cdot \mathrm{g}_{\mathrm{cat}}{ }^{-1} \mathrm{~h}^{-1}\right]}\end{array}$ & $\begin{array}{c}M_{\mathrm{n}} \\
{\left[\mathrm{kg} \cdot \mathrm{mol}^{-1}\right]}\end{array}$ & $M_{\mathrm{w}} / M_{\mathrm{n}}$ & $\begin{array}{l}T_{\mathrm{m}}^{\mathrm{e}} \\
{\left[{ }^{\circ} \mathrm{C}\right]}\end{array}$ & $\begin{array}{c}T_{\text {cryst }}{ }^{\mathrm{e}} \\
{\left[{ }^{\circ} \mathrm{C}\right]}\end{array}$ & {$\left[\begin{array}{c}{\left[m^{4}\right] \text { or }} \\
{\left[r^{4}\right]} \\
{[\%]}\end{array}\right.$} & $\begin{array}{c}\text { Comon. incorp. } \\
{[\mathrm{mol}-\%] /} \\
{[\text { comon/10 000C] }}\end{array}$ & $\begin{array}{c}\text { Comonomer } \\
\text { conv. }{ }^{\mathrm{f}}[\%]\end{array}$ \\
\hline 1 & 1 & 2.9 & 15510 & - & 0 & $60(72)$ & 21.6 & 541 & 41.0 & 2.1 & 155 & 108 & 97.7 & - & - \\
\hline 2 & 1 & 3.8 & 12000 & MHD & 1.8 & $60(75)$ & 22.2 & 370 & 13.3 & 2.7 & 144 & 107 & 93.9 & $0.37 / 12$ & 99 \\
\hline 3 & 1 & 3.8 & 11900 & MHD & 1.8 & $80(96)$ & 32.4 & 1853 & $\mathrm{nd}^{\mathrm{g}}$ & $\mathrm{nd}^{\mathrm{g}}$ & 145 & 113 & 93.6 & $0.64 / 21$ & 100 \\
\hline 4 & 2 & 8.0 & 5000 & - & 0 & $60(72)$ & 15.1 & 100 & 61.3 & 2.3 & 143 & 105 & 94.1 & - & - \\
\hline 5 & 2 & 9.3 & 4800 & MHD & 1.8 & $60(72)$ & 7.6 & 42 & 45.7 & 2.3 & 142 & 105 & 91.2 & $0.34 / 11$ & 25 \\
\hline 6 & 2 & 9.3 & 4800 & MHD & 5.2 & $60(70)$ & 5.0 & 27 & 33.3 & 2.4 & 145 & 106 & 92.1 & $0.64 / 21$ & 11 \\
\hline 7 & 2 & 11.0 & 2180 & MHD & 12.0 & $60(72)$ & 21.6 & 100 & 42.2 & 2.3 & 139 & 103 & 92.0 & $1.56 / 51$ & 56 \\
\hline 8 & 2 & 9.3 & 4800 & MHD & 12.0 & $60(68)$ & 12.7 & 76 & 44.8 & 2.3 & 141 & 108 & 92.5 & $1.59 / 52$ & 33 \\
\hline 9 & 3 & 13.3 & 3600 & - & 0 & $60(84)$ & 5.1 & 29 & 95.9 & 2.2 & 109 & 95 & 77.5 & - & - \\
\hline 10 & 3 & 9.3 & 2560 & MHD & 12.0 & $60(65)$ & 2.5 & 19 & 54.9 & 2.2 & 107 & 83 & 74.0 & $1.23 / 40$ & 6 \\
\hline $11^{\mathrm{b}}$ & 3 & 9.3 & 2560 & MHD & 12.0 & $60(66)$ & 5.3 & 20 & 54.1 & 2.2 & 107 & 85 & 74.6 & $1.17 / 38$ & 12 \\
\hline 12 & 4 & 18.0 & 1600 & - & 0 & $30(45)$ & 14.5 & 29 & 131.5 & 2.3 & no ${ }^{\mathrm{h}}$ & $\mathrm{no}^{\mathrm{h}}$ & $\mathrm{nd}^{\mathrm{h}}$ & - & - \\
\hline $13^{c}$ & 4 & 18.0 & 1600 & MHD & 12.0 & $60(65)$ & 1.4 & 2.8 & 42.7 & 2.2 & no $^{\mathrm{h}}$ & $\mathrm{no}^{\mathrm{h}}$ & $\mathrm{nd}^{\mathrm{h}}$ & $0.19 / 6$ & 0.5 \\
\hline 14 & 5 & 10.0 & 5200 & - & 0 & $60(62)$ & 10.5 & 69 & 62.5 & 2.0 & 148 & 102 & 92.2 & - & - \\
\hline 15 & 5 & 10.0 & 5200 & TMSO & 2.7 & $60(62)$ & 1.6 & 12 & 59.2 & 2.2 & 146 & 102 & 91.8 & $0.30 / 10$ & 5 \\
\hline 16 & 5 & 10.0 & 5200 & MOD & 2.2 & $60(62)$ & 0.5 & 3.5 & 63.6 & 2.5 & 145 & 103 & 91.2 & $0.30 / 10$ & 2 \\
\hline
\end{tabular}

${ }^{a}$ Conditions: $\left[\mathrm{Zr}\right.$ or Ti] $=3.8$ to $11.0 \mu$ mol. $\mathrm{L}^{-1}$, toluene $(150 \mathrm{~mL})$, in situ activation with $1,600-15,000$ equiv. MAO, $\mathrm{P}_{\text {propylène }}=5$ bar $($ i.e., [propylene] $=$ ca. 1.7 mol. $\mathrm{L}^{-1}, T_{\text {polym }}=60{ }^{\circ} \mathrm{C}$, time $=10 \mathrm{~min} .{ }^{\mathrm{b}}$ Reaction time $=20 \mathrm{~min} .{ }^{\mathrm{c}}$ Reaction time $=30 \mathrm{~min} .{ }^{\mathrm{d}}$ Values in brackets correspond to the maximal temperature reached in the reactor. ${ }^{\mathrm{e}}$ Melting $\left(T_{\mathrm{m}}\right)$ and crystallization $\left(T_{\text {cryst }}\right)$ temperatures, as determined by DSC. ${ }^{\mathrm{f}}$ Determined by ${ }^{1} \mathrm{H}(8-\mathrm{TMSO}$ and $1,6-\mathrm{MOD})$ or ${ }^{13} \mathrm{C}(\mathrm{MHD}) \mathrm{NMR}$; see the Experimental section. ${ }^{\mathrm{g}}$ Not determined as a small part of this polymer was not soluble in TCB at $135{ }^{\circ} \mathrm{C}$. ${ }^{\mathrm{h}}$ Not observed/not determined, gummy materials at room temperature. 

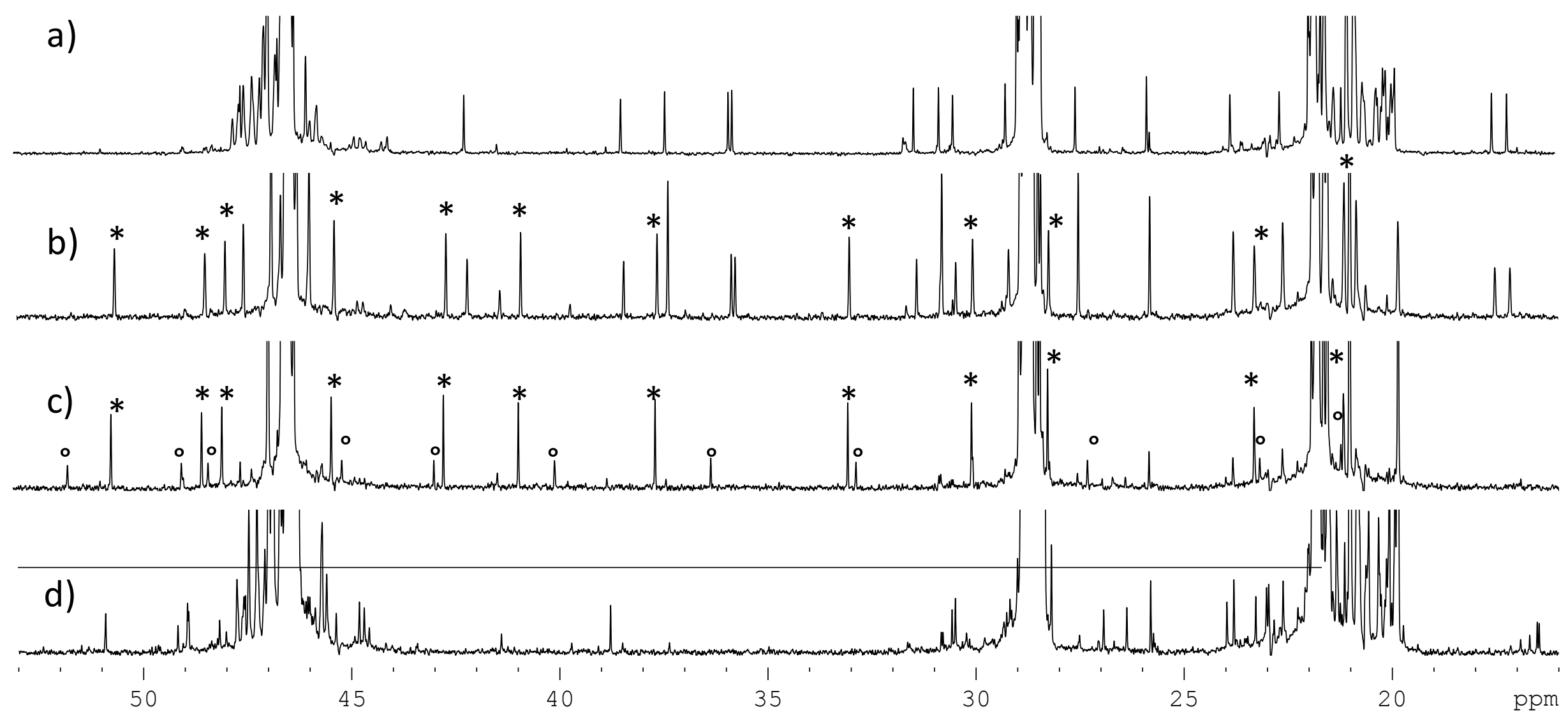

Figure 4. Detail of the ${ }^{13} \mathrm{C}\left\{{ }^{1} \mathrm{H}\right\}$ NMR spectra $\left(\mathrm{Cl}_{2} \mathrm{CDCDCl}_{2}, 125 \mathrm{MHz}, 135{ }^{\circ} \mathrm{C}\right)$ of a) an iPP homopolymer produced by $\mathbf{1} / \mathrm{MAO}(\mathrm{Table} 1$, entry

1). b) a $\mathrm{P}(\mathrm{P}-$ co-MHD) copolymer produced by $\mathbf{1} / \mathrm{MAO}$ (Table 1, entry 2); c) a $\mathrm{P}(\mathrm{P}-$ co-MHD) copolymer produced by $2 / \mathrm{MAO}$ (Table 1 , entry 6);

d) an iPP homopolymer produced by $2 / \mathrm{MAO}$ (Table 1 , entry 4). Signals corresponding to MMCP motifs are noted $*$ (major series) and ${ }^{\circ}$ (minor series). 

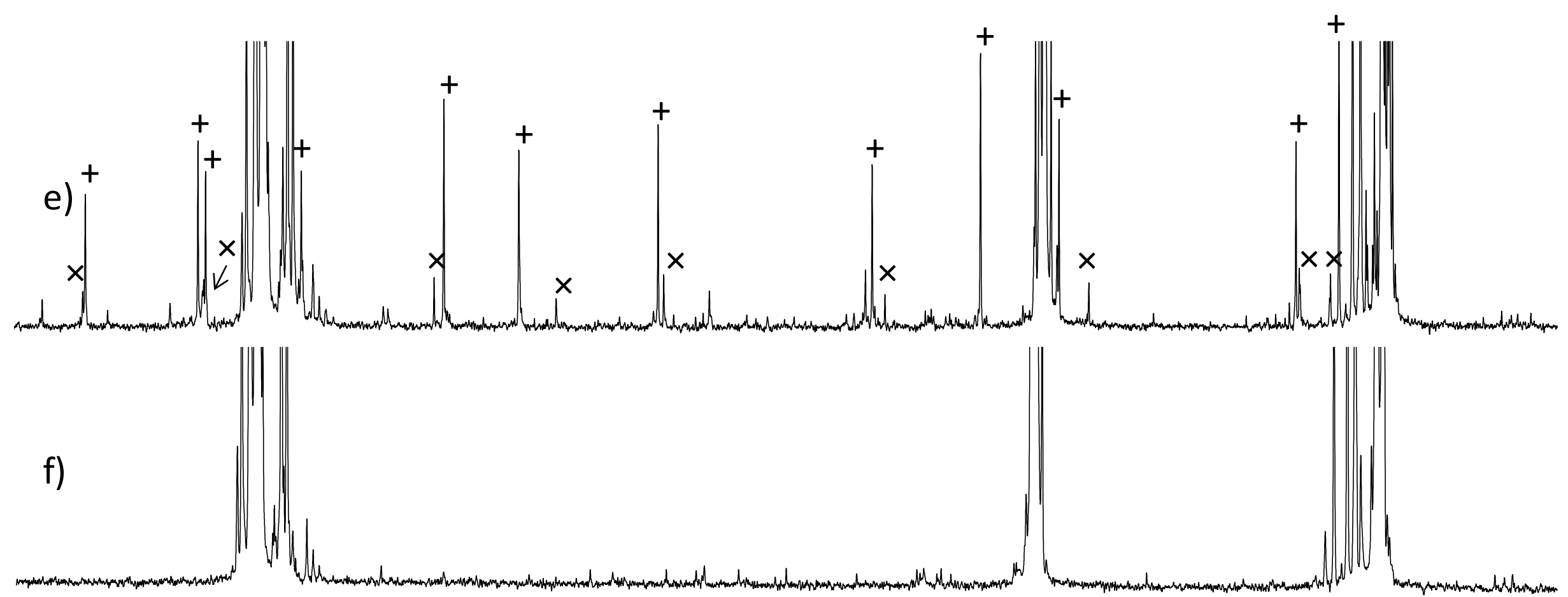

$50 \quad 45$

40

35

25

20

ppm

Figure 5. Detail of the ${ }^{13} \mathrm{C}\left\{{ }^{1} \mathrm{H}\right\}$ NMR spectra $\left(\mathrm{Cl}_{2} \mathrm{CDCDCl}_{2}, 125 \mathrm{MHz}, 135{ }^{\circ} \mathrm{C}\right)$ of e) a $\mathrm{P}(\mathrm{P}-\mathrm{co}-\mathrm{MHD})$ copolymer produced by $\mathbf{3} / \mathrm{MAO}(\mathrm{Table} 1$, entry 10); signals corresponding to MMCP motifs are noted + (major series) and $\times$ (minor series) and f) a sPP homopolymer produced by 3/MAO (Table 1, entry 9). 


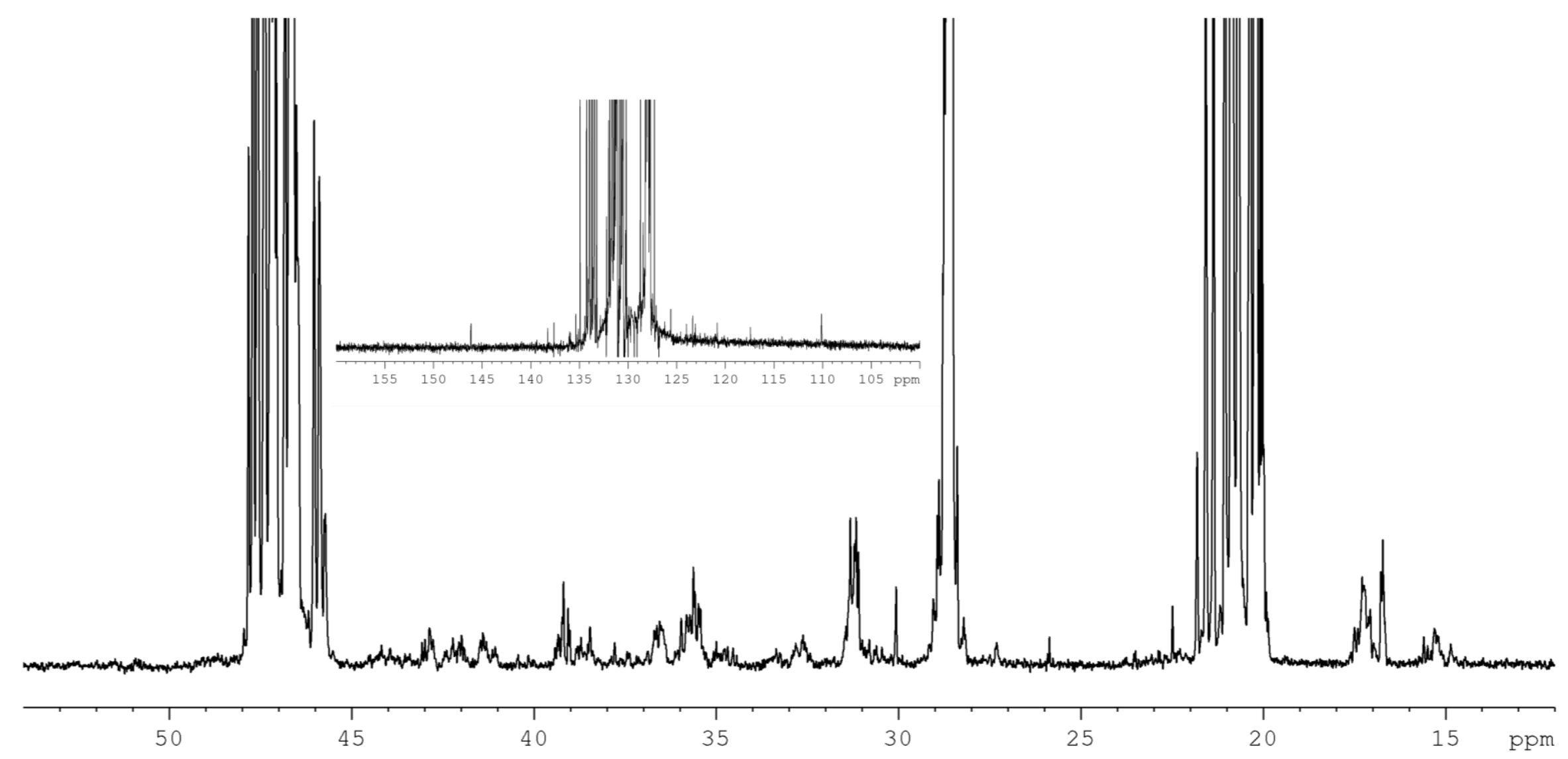

Figure 7. Details of the ${ }^{13} \mathrm{C}\left\{{ }^{1} \mathrm{H}\right\}$ NMR spectrum $\left(1,2,4\right.$-trichlorobenzene/ $\left.\mathrm{C}_{6} \mathrm{D}_{6}(5: 1), 125 \mathrm{MHz}, 135{ }^{\circ} \mathrm{C}\right)$ of a $\mathrm{P}(\mathrm{P}-\mathrm{co}$-MHD) copolymer produced by $\mathbf{4} / \mathrm{MAO}$ (Table 1 , entry 13 ) 
For the Table of content entry

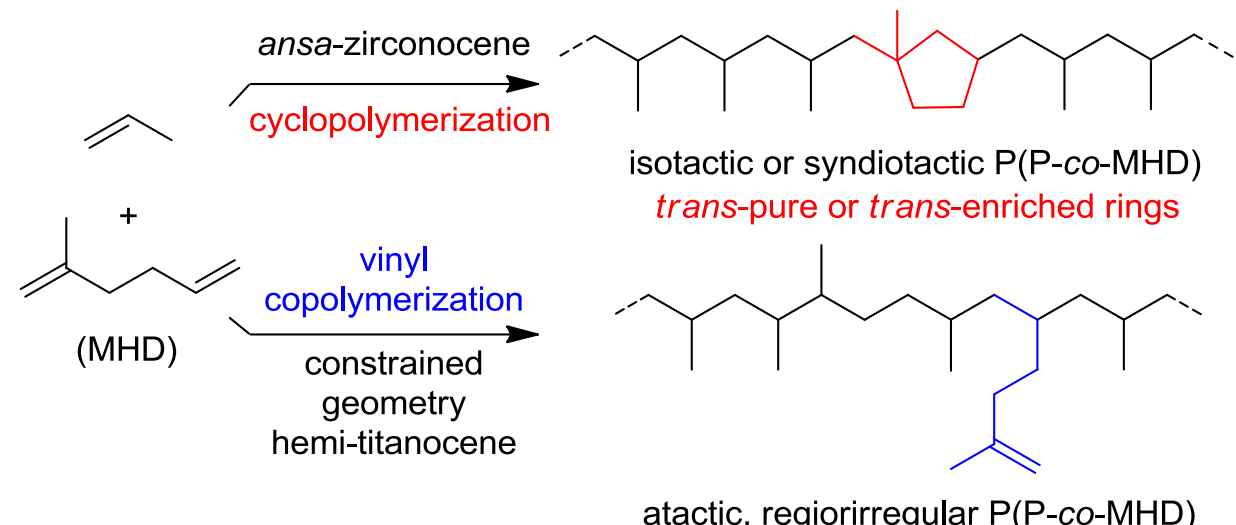

